\title{
Personality assessment in chronic pain patients
}

\author{
Avaliação da personalidade em pacientes \\ com dor crônica
}

\author{
Lucas de Francisco CARVALHO \\ Ricardo PRIMI ${ }^{1}$ \\ Cláudio Garcia CAPITÃO'
}

\begin{abstract}
In Brazil, studies investigating the personality characteristics of chronic pain patients are scarce. The present study aimed to evaluate the personality characteristics of patients with chronic pain and to compare them with those of patients without this condition. To this end, the Personality Disorders Dimensional Inventory and the Hypochondriasis scale of the Brazilian version of the Minnesota Multiphasic Personality Inventory were administered. Two different statistical analyses were carried out: the $t$ - test to determine the differences between the scores for the two groups and the logistic regression analysis to examine the predictive power of the scales for the diagnosis of chronic pain. The results revealed significant differences $(p<0.05)$ among the Histrionic, Hypochondriasis, and Sadistic scales as predictors for the groups studied, with larger effect sizes on the Histrionic and Hypochondriasis scales. The authors suggest that the use of these scales in a clinical context may provide important information for health professionals.
\end{abstract}

Keywords: Chronic pain; Histrionic personality disorders; Hypochondriasis; Personality tests.

\section{Resumo}

No Brasil, estudos investigando as características da personalidade em pacientes com dor crônica são escassos. O objetivo da presente pesquisa foi avaliar as características da personalidade em pacientes com dor crônica e compará-las com as de pessoas sem esse diagnóstico. Para tanto, foram aplicados o Inventário Dimensional de Transtornos da Personalidade e a Escala de Hipocondria da versão brasileira do Minnesota Multiphasic Personality Inventory. Duas análises estatísticas distintas foram empregadas, sendo elas o teste $t$, para verificar diferenças entre as pontuações dos dois grupos, e a análise de regressão logística, para investigar a capacidade preditiva das escalas para o diagnóstico de dor crônica. Os resultados indicaram diferenças significativas $(p<0,05)$ nas escalas Histriônico, Hipocondria e Sádico como preditores dos grupos estabelecidos, com maiores magnitudes as escalas Histriônico e Hipocondria. Os autores sugerem que o uso das escalas para o contexto clínico pode agregar informações relevantes para o profissional.

Palavras-chave: Dor crônica; Transtornos da personalidade histriônica; Hipocondríase; Testes de personalidade.

\footnotetext{
$\Delta \nabla v$

1 Universidade São Francisco, Faculdade de Psicologia, Programa de Pós-Graduação Stricto Sensu em Psicologia. R. Alexandre Rodrigues Barbosa, 45, 13251-900, Itatiba, SP, Brasil. Correspondência para/Correspondence to: L.F. CARVALHO. E-mail: <lucas@labape.com.br>. Support: Fundação de Amparo à Pesquisa do Estado de São Paulo and Conselho Nacional de Desenvolvimento Científico e Tecnológico.
} 
Chronic pain is characterized by pain that persists over a long period of time and may be related to chronic pathological processes (Merskey, 1994; Shipton \& Tait, 2005). Although few studies in Brazil have examined chronic pain and its related factors (Sa, Baptista, Matos, \& Lessa, 2009), a study carried out by the World Health Organization (Gureje, Von Korff, Simon, \& Gater, 1998) revealed that $31.0 \%$ of the Brazilian population are newly diagnosed with chronic pain each year. Consistent with these findings, a study conducted by Sa et al. (2009), involving participants from the city of Salvador (BA), found that $41.4 \%(N=2297)$ of the population studied were diagnosed with chronic pain.

Among the many factors related to chronic pain, it is clear that psychological factors play an important role in this pathology, especially in the cases in which a diagnosis of psychiatric disorders has been established (Karlin et al., 2005). As mentioned by Dersh, Gatchel, Mayer, Polatin, and Temple (2006), several studies have documented a higher prevalence of depression, anxiety, abuse/ dependence of substances, somatization, and personality disorders in patients with chronic pain, as compared with the general population. Unrecognized and untreated psychopathologies can significantly interfere with the rehabilitation of patients with chronic pain and may worsen the problems of coping with pain and affect the perception of pain (Dersh et al., 2006; P. Fietta, Fietta, \& Manganelli, 2007; Haggard et al., 2008). These results suggest that the assessment and treatment of psychopathologies are critical to the recovery of patients with chronic pain.

Among the different psychiatric disorders listed in the literature, major depressive disorder (axis I Diagnostic and Statistical Manual of Mental Disorders - Fourt Edition - Text Revision [DSM-IV-TR], American Psychiatric Association, 2003) and personality disorders are some of the most common in patients diagnosed with chronic pain (Massie, 2000; Weisberg, 2000; Weisberg \& Boatwright, 2007). Additionally, Weisberg and Keefe (1997) argue that an accurate diagnosis of personality disorders can be beneficial if used appropriately to guide treatment decisions, emphasizing the importance of personality assessment in patients with chronic pain (Karlin et al., 2005).

Several studies have investigated the relationship between personality and personality disorders in patients with chronic pain. Haggard et al. (2008) administered the third version of the Millon Clinical Multiaxial Inventory (MCMI-III) to 78 patients diagnosed with chronic pain. The results demonstrated that the patients had higher MCMIIII scores and significantly more psychiatric disorders when compared with the general population. Nearly $95.0 \%$ of the patients in the sample displayed symptoms related to psychiatric disorders, and at least $69.0 \%$ of the patients met the criteria for a diagnosable psychiatric disorder and $53.8 \%$ of the patients in the sample met criteria for a personality disorder. The authors also reported the prevalence of each specific disorder.

Uomoto, Turner, and Herron (1988) also used the MCMI (first version) and the first version of the Minnesota Multiphasic Personality Inventory (MMPI) to determine which instrument had the best prediction power when examining chronic pain reduction in 129 patients after a surgical intervention. The authors concluded that both inventories had similar prediction power although different characteristics were evaluated. More specifically, the MMPI scales with the highest predictive power were Hypochondria, Defense, and Lie, and the MCMI scales with the highest prediction power were Dependent, Avoidant, Anxiety, Psychotic Thinking, Alcohol Abuse, and Histrionic.

In a similar study, Dersh et al. (2006) found that $70.0 \%$ of 1,323 patients diagnosed with chronic pain were also diagnosed with at least one personality disorder. The most frequent disorders found in this population were paranoid (30.8\%) and borderline personality disorders (27.9\%), and the least prevalent disorders were schizoid $(2.6 \%)$, schizotypal (4.5\%), and antisocial personality disorders (4.5\%). Furthermore, patients with chronic pain had significantly higher scores than those of the general population for the following disorders: paranoid, antisocial, borderline, histrionic, narcissistic, avoidant, and obsessive-compulsive disorder. 
In order to compare personality characteristics, Conrad et al. (2007) assessed 207 patients with chronic pain and 105 participants without chronic pain using multiple tests including the Temperament and Character Inventory (TCl) and the Structured Clinical Interview for DSM Axis II (SCID-II). They found that $41.0 \%$ of patients and $7.0 \%$ of participants without chronic pain were diagnosed with personality disorders. Furthermore, $24.0 \%$ of patients with chronic pain had more than one personality disorder. The most frequent diagnoses of personality disorders among the patients were paranoid (12.0\%) and borderline (11.0\%), and the least common diagnoses were antisocial (2.0\%), narcissistic (3.0\%), and histrionic (3.0\%).

In addition to the empirical studies discussed above, Weisberg (2000) conducted a literature review and reported that the prevalence of personality disorders varies between 31.0 and $59.0 \%$ in individuals with chronic pain and between 0.5 and $3.0 \%$ in the general population. However, the diagnosis of personality disorders most often found in studies on patients with chronic pain varies considerably. Nevertheless, the author stated that among six of the studies reviewed, the most prevalent personality disorders found were obsessive-compulsive disorder (4studies), borderline personality disorder and paranoid disorder (3 studies), and dependent disorder and passive-aggressive disorder (2 studies).

The most widely used method for personality assessment in patients with chronic pain is the MMPI (Weisberg, 2000). In the first studies that used the MMPI to assess patients with chronic pain, a hypothesis about the conversion $\mathrm{V}$ or neurotic triad was proposed, indicating the prevalence of high scores on the hypochondriasis, depression and histrionic/hysteria scales; depression had the lowest score among all scales. According to Mongini et al. (2009), patients with chronic pain assessed by the MMPI can be categorized into several groups: Coper (moderate scores in all scales), Depressive (high scores for Hypochondriasis, depression, histrionics/ hysteria scales, and the highest score for depression scale), Conversive (high scores for the hypochondriasis, depression, histrionics/hysteria scales, with lower scores for depression scale compared with those of the other groups), and Emotionally Overwhelmed (high scores for hypochondriasis, depression, histrionics/hysteria scales, and at least one more scale). It is worth mentioning that histrionic and hypochondriac functioning have common characteristics, such as somatic symptoms (Bianchini, Etherton, Greve, Heinly, \& Meyers, 2008; Fishbain, Lewis, Gao, Cole, \& Rosomoff, 2009; Süllwold, 1990).

Michelotti, Martina, Russo, and Romeo (1998) assessed 15 patients diagnosed with chronic pain using MMPI. The results suggest that most patients had high neurotic triad scores and pathological values of hypochondriasis and histrionic/hysteria. Similar results were also found by Karakurum et al. (2004) in a study in which 37 patients with chronic pain and 50 control participants were evaluated using the MMPI. It was found that the group with chronic pain had higher scores for the neurotic triad on the scales of the MMPI than the control group.

Applegate et al. (2004) conducted a study with 2,332 individuals assessed by the MMPI to examine the extent to which personality traits would be able to predict reports of pain 30 years after a chronic pain diagnosis. The results showed that the hypochondria and histrionics/hysteria scales were more related to reports of pain in individuals with chronic pain than the other scales. Corroborating this finding, Bianchini et al. (2008) found that the hypochondria and histrionics/hysteria scales were effective in distinguishing between groups of patients with chronic pain $(N=89)$ and normal patients $(\mathrm{N}=26)$.

Other studies do not corroborate the data found in the literature regarding the personality characteristics of patients with chronic pain (Weisberg, 2000). For example, Karlin et al. (2005) found that 432 individuals diagnosed with chronic pain tended to show characteristics similar to the general population when they were assessed using the Personality Assessment Inventory (PAI). These results suggest the need for continued research in this area to explain the inconsistencies found in the literature. 
The present study aimed to evaluate the personality characteristics of patients with chronic pain and to compare them with patients without this condition. Three hypotheses, based on previous results found in the literature, were formulated and tested by assessing and comparing the personality characteristics of patients with chronic pain with those of a sample of normal patients. The first hypothesis examined whether individuals in the Chronic Pain Group (CPG) had higher scores in general when compared with the Control Group (CG). The second hypothesis was that the Hypochondriasis, Depressive and Histrionic scale scores would indicate the greatest differences between people diagnosed with chronic pain and those without this diagnosis. Finally, the third hypothesis was that the Depressive, Histrionic, and Hypochondriasis scales were more capable of predicting differentiation between CPG and CG individuals than other scales measuring personality characteristics.

\section{Method}

\section{Participants}

In the present study a correlational design was used, and it included a nonrandom sample of 60 individuals who were separated into two different groups. The first group (CPG, $N=30$ ) was composed of individuals who had been previously diagnosed with chronic pain, according to the self-report of the participant. The second group (CG, $\mathrm{N}=30$ ) was composed of individuals without a diagnosis of chronic pain. The CPG group was composed of patients undergoing treatment in a general hospital $(N=13)$ and employees of a company $(N=17)$; the $C G$ group was composed of college students. The age of the 60 participants ranged from 21 to 77 years, and $45(75.0 \%)$ patients were female. Regarding to age and educational level of the participants, there was a balance between the groups. The sampling procedure adopted was convenience sampling, and sample size calculations were not used. The participants were not asked how long they had been experiencing the pain, which should be considered as a limitation of the present study.

\section{Instruments}

Personality traits were assessed using the Personality Disorders Dimensional Inventory (IDTP) (Carvalho, 2008; Carvalho \& Primi, 2009) and the Hypochondriasis scale of the Brazilian version, developed by Benkö and Simões, of the Minnesota Multiphasic Personality Inventory (MMPI) (Hathaway \& McKinley, 1943).

The Personality Disorder Dimensional Inventory is a self-reporting inventory used to assess personality disorders, and it was developed according to the theory of Millon (Millon \& Grossman, 2007a, 2007b). This test consists of 100 questions divided into 15 scales, namely Schizoid, Avoidant, Depressive, Dependent, Histrionic, Narcissistic, Antisocial, Sadistic, Compulsive, Negativistic, Masochistic, Paranoid, Schizotypal, Borderline, and the Validity and Social Desirability scale. Each question should be answered on a 4-point scale.

Carvalho (2008) carried out a validity study seeking evidence of validity with 350 subjects including patients and healthy individuals (aged between 18 and 67 years, Mean $-M=27.02$, Standard Deviation $-S D=10.13$, and $71.3 \%$ of the sample were female). The scale reliability ranged from 0.61 (Narcissistic scale) to 0.87 (Depressive scale). The reliability indices found for the IDTP scales in the present study resemble those reported by Carvalho (2008). Validity studies have shown that the clinical group had significantly higher scores than those of the control group. Moreover, the use of the Item Response Theory demonstrated that the inventory scales were appropriate for the assessment of personality functioning in a more pathological continuum (e.g., Carvalho, 2008; Carvalho, Gurgel, \& Primi, 2011; Carvalho, Primi, \& Meyer, 2012). The MMPI Hypochondriasis Scale was also administered, and it consists of 33 items that are intended to measure the individual's level of concern about his/her bodily functions; it had the dichotomous answer format of true or false. The scale reliability 
for the present study was 0.43 . This low reliability value is not surprising since the MMPI was developed using a different approach based on criterion validity and not on internal structure consistency.

\section{Procedures}

This study was approved by the Research Ethics Committee for Data Collection (Process $n^{\circ}$ 0144.0.142.000-07), and the participants in both groups were given the free and informed consent. The participants that agreed to participate in the research answered the inventory questions individually. The differences between the means of the two groups, CPG and CG, were tested using $t$ - tests, followed by a logistic regression to determine which scales most effectively differentiated chronic pain patients from the control group when examining personality traits. It is worth mentioning that the authors, who carried out the statistical analyzes, were not "blind" to the groups (CPF and CG).

\section{Results and Discussion}

Firstly, the significant differences between the test scores of the individuals in the CPG and $C G$ were investigated. The findings suggested significant differences between the groups $(p<0.05)$ for eight of the 15 scales, including Depressive, Schizoid, Paranoid, Masochistic, Dependent, Histrionic, Negativistic, and Hypochondriasis (Table 1). Similarly, the measure of effect size, Cohen's $d$, showed that the Histrionic and Hypochondriasis scales were the ones that best discriminated between the two groups. The CPG had the highest average scores on both of these scales, a result that is similar to those found for the other scales analyzed in this study.

It was expected that patients with chronic pain would have higher scores than those in the $C G$, supporting the finding that individuals diagnosed with chronic pain tend to have higher scores on the clinical scales (Dersh et al., 2006; Fietta et al.,
2007, Karlin et al., 2005). Accordingly, the findings of this study support the first hypothesis. In addition, the high Cohen's d value expressing the differences between the means of the groups on the Histrionic and Hypochondriasis scales is in agreement with the results reported in many studies, including Bianchini et al. (2008), Merskey (1981), and Uomoto et al. (1988). Similarly, Dersh et al. (2006) found histrionic disorder to be significantly more prevalent in the clinical population than in the general population. Therefore, the second hypothesis of this study was partially supported since the Hypochondriasis and Histrionic scales showed the greatest differences between the groups. The difference between groups was somewhat significant for the Depressive Scale. Five other scales, the Masochist, Negativistic, Schizoid, Paranoid, and Dependent were not hypothesized to differentiate between groups, yet they showed significant differences. Future studies are needed to investigate the characteristics assessed on these scales in order to better explain the data found.

Logistic regression allows the estimation of the probability that an individual belongs to a group of patients. For each coefficient, logistic regression provides the Wald statistic, which indicates whether the coefficient is statistically different from zero (Tabachinick \& Fidell, 1996). In the analysis, scale scores on the IDTP and the Hypochondriasis Scale of the MMPI were considered independent variables. The stepwise variable selection, forward method, was used to determine which variables were included in the regression equation. Table 2 shows the results of the logistic regression. The $B$ parameters of three variables were included in the regression equation based on a significance criterion of $p<0.15$

Of the 15 independent variables investigated, the three variables that were retained in the logistic regression equation were Histrionic, Sadistic, and Hypochondria (Table 2). The three variables combined were able to predict $49.0 \%$ of the variance (see $R^{2}$ column in Table 2 ) in the chronic pain diagnosis data. The use of these three variables resulted in correct prediction rates of $73.3 \%$ ( 22 
Table 1

Comparison between the mean values of CPG and CG for the Hypochondriasis Scale and IDTP

\begin{tabular}{|c|c|c|c|c|c|c|c|c|}
\hline Factors & Group & $\mathrm{N}$ & Mean & $S D$ & $t$ & $d f$ & $p$-value & $d$ \\
\hline \multirow[t]{2}{*}{ Depressive } & CPG & 30 & 1.73 & 0.68 & \multirow{2}{*}{2.505} & \multirow{2}{*}{58} & \multirow{2}{*}{0.01} & \multirow{2}{*}{0.66} \\
\hline & $C G$ & 30 & 1.35 & 0.45 & & & & \\
\hline \multirow[t]{2}{*}{ Schizoid } & CPG & 30 & 1.69 & 0.61 & \multirow{2}{*}{2.358} & \multirow{2}{*}{58} & \multirow{2}{*}{0.02} & \multirow{2}{*}{0.62} \\
\hline & $C G$ & 30 & 1.37 & 0.41 & & & & \\
\hline \multirow[t]{2}{*}{ Borderline } & CPG & 30 & 2.23 & 0.57 & \multirow{2}{*}{0.937} & \multirow{2}{*}{58} & \multirow{2}{*}{0.35} & \multirow{2}{*}{0.23} \\
\hline & $C G$ & 30 & 2.10 & 0.57 & & & & \\
\hline \multirow[t]{2}{*}{ Paranoid } & CPG & 28 & 1.96 & 0.61 & \multirow{2}{*}{2.218} & \multirow{2}{*}{58} & \multirow{2}{*}{0.03} & \multirow{2}{*}{0.59} \\
\hline & $C G$ & 30 & 1.64 & 0.47 & & & & \\
\hline \multirow[t]{2}{*}{ Sadistic } & CPG & 30 & 1.52 & 0.45 & \multirow{2}{*}{1.154} & \multirow{2}{*}{58} & \multirow{2}{*}{0.25} & \multirow{2}{*}{0.29} \\
\hline & $C G$ & 30 & 1.39 & 0.44 & & & & \\
\hline \multirow[t]{2}{*}{ Compulsive } & CPG & 30 & 2.73 & 0.67 & \multirow{2}{*}{-0.182} & \multirow{2}{*}{58} & \multirow{2}{*}{0.85} & 0.05 \\
\hline & $C G$ & 30 & 2.76 & 0.51 & & & & \\
\hline Masochistic & CPG & 30 & 1.75 & 0.58 & 2.779 & 58 & 0.01 & 0.73 \\
\hline & $C G$ & 30 & 1.39 & 0.38 & & 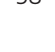 & & \\
\hline Antisocial & CPG & 30 & 1.56 & 0.46 & 0340 & 58 & 073 & (ח09 \\
\hline & $C G$ & 30 & 1.52 & 0.43 & 0.340 & 50 & 0.13 & 0.09 \\
\hline Dependent & CPG & 30 & 1.72 & 0.67 & 2030 & 58 & 005 & 0.52 \\
\hline & CG & 30 & 1.42 & 0.46 & 2.050 & 50 & 0.05 & 0.32 \\
\hline Histrionic & CPG & 30 & 1.75 & 0.45 & 3263 & 58 & 001 & 085 \\
\hline & $C G$ & 30 & 1.38 & 0.42 & 3.205 & 0 & 0.01 & S.05 \\
\hline Negativistic & CPG & 30 & 1.75 & 0.63 & 2686 & 58 & 001 & 069 \\
\hline & $C G$ & 30 & 1.38 & 0.42 & & & 0.01 & 3.05 \\
\hline Schizotypal & CPG & 30 & 1.89 & 0.70 & 1711 & 58 & 010 & 043 \\
\hline & $C G$ & 30 & 1.62 & 0.53 & דוז. & & 0.10 & 0.45 \\
\hline Phobic (Avoidant) & CPG & 30 & 1.90 & 0.65 & 1833 & 58 & 007 & 049 \\
\hline & $C G$ & 30 & 1.62 & 0.49 & & & 0.07 & 0.43 \\
\hline Narcissist & CPG & 30 & 2.02 & 0.53 & -0.429 & 58 & 0.67 & 012 \\
\hline & CG & 30 & 2.08 & 0.47 & & & & 0.12 \\
\hline Hypochondriasis & CPG & 29 & 1.56 & 0.10 & 3636 & 58 & 001 & 100 \\
\hline & CG & 30 & 1.46 & 0.10 & & & & \\
\hline
\end{tabular}

Note: CPG: Chronic Pain Group; CG: Control Group; SD: Standard Deviation; df: degrees of freedom; d: Cohen's d.; IDTP: Personality Disorders Dimensional Inventory.

Table 2

Global results of Logistic Regression Analysis

\begin{tabular}{lccccccc}
\hline Independent Variables & $\beta$ & S.E. & Wald & df & $p$ & $R^{2^{*}}$ & Exp $(\beta)$ \\
\hline Histrionic Scale & 2.058 & 1.049 & 3.850 & 1 & 0.050 & 0.229 & 7.831 \\
Sadistic Scale & -3.610 & 1.129 & 10.231 & 1 & 0.001 & 0.421 & 0.027 \\
Hypochondria Scale & -13.138 & 4.083 & 10.354 & 1 & 0.001 & 0.490 & 0.000 \\
Constant & 22.598 & 6.499 & 12.092 & 1 & 0.001 & & \\
\hline
\end{tabular}

Note: " $R^{2}$ corresponds to the Nagelkerke $R^{2}$; Nagelkerke's $R^{2}$ ranges from 0 to 1 (Harris, 2005). For this analysis, all scales of the Personality Disorders Dimensional Inventory (IDTP) and the Hypochondria Scale were used, but only those that showed significance in the mathematical model are shown.

650 $\beta$ : Beta; S.E.: Standard Error; df: degrees of freedom; $\operatorname{Exp}(\beta)$ : $\beta$ exponentiated coefficient. 
cases correctly classified among the 30 CPG patients) and $76.7 \%$ (23 cases among 30 individuals correctly classified as belonging to the CG). The overall prediction success rate was $75.0 \%$.

In addition, it is important to note that the Depressive Scale showed a non-significant contribution to the logistic regression. Interestingly, two scales (Hypochondria and Histrionic) with higher degree of construct specificity contributed to the prediction. The characteristics evaluated using these two scales are typically correlated with depression symptoms, which justifies their inclusion in the regression equation. At the same time, these two scales provide more detailed information about the psychological functioning than general depression would provide since general depression indicates only a general distress commonly experienced by patients with a great spectrum of psychological problems. It should be noted that studies based on data derived from scales that measure depression symptoms of the DSM-IV-TR axis I (American Psychiatric Association, 2003) also show the Major Depressive Disorder to be a relevant comorbidity in patients with chronic pain, but the IDTP (the inventory used in the present study) aims to conduct evaluations according to axis II.

On the one hand, these data are consistent with empirical data found in other studies (Applegate et al., 2004; Bianchini et al., 2008), which suggested that the Histrionic and Hypochondriasis scales are the best predictors of chronic pain. On the other hand, no data were found in the literature to support the findings that the Sadistic Scale contributed significantly to differentiating between patients with chronic pain and normal patients. Thus, the third hypothesis of this study was partially supported. It is noteworthy that the causal relationships between the many types of chronic pain and depression and anxiety processes have not yet been fully understood, according to the current knowledge of neurophysiopsychological mechanism interactions.

\section{Conclusion}

The aim of the present study was to assess the personality characteristics in patients with chronic pain and to compare them with those of normal patients. The findings partially corroborate the initial hypotheses, which were based on the literature review. Furthermore, some study limitations should be considered when analyzing the results. The main limitations are related to the sample, i.e., a small and non-randomized sample was used, and there was little knowledge about the chronic pain history of the patients in the sample.

Specifically, the first hypothesis was supported because individuals in the CPG had higher scores on all scales than those in the CG. With regard to the second hypothesis, two scales (Histrionic and Hypochondriasis), of the three scales specified in the hypothesis (Depression, Histrionic and Hypochondriasis), showed significant differences between the groups. The third hypothesis (i.e., the scales with more predictive power would be Depression, Histrionic, and Hypochondriasis) was partially supported because the Depression scale did not have a sufficiently high score for the CPG. Therefore, future studies should investigate the relationship between personality characteristics related to masochistic, negativistic, and sadistic functioning and patients diagnosed with chronic pain.

Although further studies using the same methods used in the present study are needed, the findings obtained suggest that the use of the Histrionic and Sadistic scales of the IDTP and the Hypochondriasis scale of the MMPI can significantly contribute to the clinical evaluations of patients with chronic pain that are suspected of having personality disorders. Using these two tests can help the clinician to predict personality pathological functioning. Furthermore, these data are consistent with results reported in the international literature that indicate, in the context of psychotherapy, a relationship between chronic pain diagnosis and histrionic and hypochondriac patients. Moreover, the Sadistic Scale can contribute to the differential diagnosis because there is a close relationship between sadistic and antisocial psychologies. However, although sadism and psychopathy are highly correlated, they are not identical. For example, not all psychopathic people are notably 
sadistic, and not all sadistic people are psychopathic. Future studies should seek to replicate the administration of the IDTP in a sample of patients with chronic pain, but they should also use methods that access depression as an axis I disorder.

\section{Contributors}

L.F. CARVALHO and R. PRIMI contributed to the design and conception of this study, data analyses, and writing and revising of the manuscript. C.G. CAPITÃO contributed to the conception of this study and the writing and revising of the manuscript.

\section{References}

American Psychiatric Association. (2003). Manual diagnóstico e estatístico de transtornos mentais DSM-IV-TR ( $4^{\mathrm{a}}$ ed.). Porto Alegre: Artmed.

Applegate, K. L., Keefe, F. J., Siegler, I. C., Bradley, L. A., McKee, D. C., Cooper K. S., \& Riordan, P. (2004). Does personality at college entry predict number of reported pain conditions at mid-life? A longitudinal study. The Journal of Pain, 6(2), 92-97.

Bianchini, K. J., Etherton, J. L., Greve, K. W., Heinly, M. T., \& Meyers, J. E. (2008). Classification accuracy of mmpi-2 validity scales in the detection of pain-related malingering. Assessment, 15(14), 435-449.

Carvalho, L. F. (2008). Construção e validação do inventário dimensional dos transtornos da personalidade (Dissertação de mestrado não-publicada). Universidade São Francisco, Itatiba. Recuperado em dezembro 20, 2012, de http://www.saofrancisco.edu.br/itatiba/ mestrado/psicologia/uploadAddress/Dissertacao_ VersaoFinal3[10989].pdf

Carvalho, L. F., Gurgel, M. G. A., \& Primi, R. (2011). Evidências de validade do IDTP por meio da versão brasileira do TIPI. Psicologia Hospitalar, 9(1), 2-23.

Carvalho, L. F., Primi, R., \& Meyer, G. J. (2012). Aplicação do modelo de Rasch na medida de transtornos da personalidade. Trends in Psychiatry and Psychotherapy, 34(2), 101-109.

Carvalho, L. F., \& Primi, R. (2009). Development of a Brazilian Inventory for the Assessment of Personality Disorders based on Millon's model. Work presented at the SPA Annual Meeting, Chicago, EUA.

Conrad, R., Schilling, G., Bausch, C., Nadstawek, J., Wartenberg, H. S., Wegener, I., ... Liedtke, R. (2007). Temperament and character personality profiles and personality disorders in chronic pain patients. Pain, 133(1-3), 197-209.
Dersh, J., Gatchel, R. J., Mayer, T., Polatin, P., \& Temple, O. R. (2006). Prevalence of psychiatric disorders in patients with chronic disabling occupational spinal disorders. SPINE, 31(10), 1156-1162.

Fietta, P., Fietta, P., \& Manganelli, P. (2007). Fibromyalgia and psychiatric disorders. Acta Biomed, 78(2), 88-95.

Fishbain, D. A., Lewis, J. E., Gao, J., Cole, B., \& Rosomoff, S. (2009). Is chronic pain associated with somatization/ hypochondriasis? An evidence-based structured review. Pain Practice, 9(6), 449-467.

Gureje, O., Von Korff, M., Simon, G. E., \& Gater, R. (1998). Persistent pain and well-being: A World Health Organization study in primary care. Journal of American Medical Association, 280(2), 147-151.

Haggard, R., Stowell, A., Gatchel, R., Bernstein, D., Overman, T., McManemin, ... Garland, G. (2008). MCMI-III as a method to compare the prevalence of psychiatric disorders in patients with chronic pain. The Journal of Pain, 9(4-2), 67.

Harris, R. J. (2005). Analysis of variance: Multiple regression approaches. In B. S. Everitt \& D. Howell (Eds.), Encyclopedia of Statistics in Behavioral Science. New Jersey: Wiley.

Hathaway, S. R., \& McKinley, J. C. (1943). Minnesota multiphasic personality schedule. Minneapolis: University of Minnesota Press.

Karlin, B. E., Creech, S. K., Grimes, J. S., Clark, T. S., Meagher, M. W., \& Morey, L. C. (2005). The Personality Assessment Inventory with chronic pain patients: Psychometric properties and clinical utility. Journal of Clinical Psychology, 61(12), 1571-1585.

Karakurum, B., Soylu, Ö., Karatas, M., Giray, S., Tan, M., \& Arlier, Z. (2004). Personality, depression, and anxiety as risk factors for chronic migraine. International Journal of Neuroscience, 114(11), 1391-1399.

Massie, M. J. (2000). Personality characteristics of patients with pain book review. Psychiatric Services, 52(2), 247.

Merskey, H. (1981). Headache and hysteria. Cephalalgia, 1(2), 109-119.

Merskey, H. (1994). Logic, truth and language in concepts of pain. Quality of Life Research, 3(Supl.1), 569-576.

Michelotti, A., Martina, R., Russo, M., \& Romeo, R. (1998). Personality characteristics of temporomandibular disorder patients using M.M.P.I. Cranio, 16(2), 119-125.

Millon, T., \& Grossman, S. (2007a). Moderating severe personality disorders. New Jersey: Wiley.

Millon, T., \& Grossman, S. (2007b). Overcoming resistant personality disorders. New Jersey: Wiley.

Mongini, F., Rota, E., Evangelista, A., Ciccone, G., Milani, C., Ugolini, A., ... Rosato, R. (2009). Personality profiles and subjective perception of pain in head pain patients. Pain, 144(1-2), 125-129. 
Sa, K. N., Baptista, A., Matos, M. A., \& Lessa, I. (2009). Prevalência de dor crônica e fatores associados na população de Salvador, Bahia. Revista de Saúde Pública, 43(4), 622-630.

Shipton, E. A., \& Tait, B. (2005). Flagging the pain: Preventing the burden of chronic pain by identifying and treating risk factors in acute pain. European Journal of Anaesthesiology, 22(6), 405-412.

Süllwold, F. (1990). Structure of the hypochondriacal and hysteroid personality. Zeitschrift fur Experimentelle und Angewandte Psychologie, 37(4), 642-659.

Tabachinick, B. G., \& Fidell, L. S. (1996). Using multivariate statistics. New York: Harper Collins.

Uomoto, J. M., Turner, J. A., \& Herron, L. D. (1988). Use of the MMPI and MCMI in predicting outcome of lumbar laminectomy. Journal of Clinical Psychology, 44(2), 191-197.

Weisberg, J. N. (2000). Personality and personality disorders in chronic pain. Current Review of Pain, 4(1), 60-70.

Weisberg, J. N., \& Boatwright, B. A. (2007). Mood, anxiety and personality traits and states in chronic pain. Pain, 133(1-3), 1-2.

Weisberg, J. N., \& Keefe, F. J. (1997). Personality disorders in the chronic pain population: Basic concepts, empirical findings, and clinical implications. Pain Forum, 6(1), $1-9$.

Received: March 16, 2013

Final version: May 16, 2014

Approved: September 2, 2014 
